\title{
PENINGKATAN KEMAMPUAN MEMAHAMI TEKS NARATIVE DENGAN METODE LEARNING BY DOING DI MASA PANDEMI SECARA DARING
}

\author{
MIFTAHUL HIDAYAH \\ SMP Negeri 2 Kepanjen \\ Email : miftahul19hidayah@gmail.com
}

\begin{abstract}
ABSTRAK
Masa pandemi covid 19 telah membuat dunia pendidikan harus mengubah sistemnya dan menggunakan paradigma baru untuk menghadapi masalah yang mulai muncul. Pemerintah membuat kebijakan yang mengesahkan kemerdekaan dalam belajar di era baru. Semua lapisan masyarakat harus menyiapkan diri untuk melakukan pembelajaran tanpa tatap muka melalui kegiatan online dengan memanfaatkan teknologi dalam kerangka belajar dari rumah. Pembelajaran di selenggarakan dengan menggunakan media online memberikan kesempatan kepada siswa untuk mengembangkan diri secara mandiri dengan dipandu oleh guru dalam pembelajaran jarak jauh (PJJ) melalui kelas online. Banyak masalah baru yang muncul, bukan hanya dihadapi siswa tapi juga oleh orang tua siswa dan guru. Hal ini disebabkan oleh belum terbiasa dengan PJJ. Masalah yang dihadapi guru adalah sulitnya mengontrol siswa apalagi membuat mereka belajar dengan serius dan efektif. Masalah yang dihadapi orang tua siswa adalah bukan hanya mereka tidak mempunyai kemampuan secara finansial untuk menyediakan perangkat teknologi informasi untuk melakukan kegiatan belajar tapi juga mereka tidak memiliki kemampuan kognitif yang cukup untuk mendampingi putra putrinya menyelesaikan masalah dalam pelajaran, Sehingga metode menarik diperlukan untuk menyelesaikan masalah ini. Bahasa Inggris sebagai bahasa asing adalah masalah besar bagi siswa dan orang tua untuk melakukan pembelajaran tanpa pendampingan guru secara langsung. Apalagi teks naratif adalah materi sulit untuk siswa SMP Negeri 2 Kepanjen kuasai. Peneliti menemukan bahwa metode learning by doing yang digagas oleh Dewey akan membantu peserta didik untuk lebih memahami teks naratif.Peneliti mencoba menerapkan metode ini kepada siswa kelas 9ASMP N 2 kepanjen tahun pelajaran 2020-2021. Setelah menerapkan metode yang digagas oleh Dewey ini ada peningkatan yang cukup signifikan dalam kemampuan memahami teks naratif. Ini bisa di lihat dari nilai yang mereka dapatkan. Kenaikan nilai mencapai 31,4\%.
\end{abstract}

Kata Kunci : Teks Naratif, Metode Learning by doing, masa pandemi, daring

\section{ABSTRACT}

The COVID-19 pandemic has forced the world of education to change its system and use a new paradigm to deal with emerging problems. The government made a policy that ratified the independence of learning in the new era. All levels of society must prepare themselves to do face-to-face learning through online activities by utilizing technology within the framework of learning from home. Learning held using online media provides opportunities for students to develop themselves independently, guided by teachers in distance learning (PJJ) through online classes. Many new problems arise, not only faced by students but also by parents and teachers. This is due to not being familiar with PJJ. The problem faced by teachers is that it is difficult to control students let alone make them study seriously and effectively. The problem faced by parents is that not only do they not have the financial ability to provide information technology tools to carry out learning activities but also they do not have sufficient cognitive abilities to assist their sons and daughters in solving problems in lessons, so interesting methods are needed to solve this problem. . English as a foreign language is a big problem for students and parents to carry out learning without direct teacher assistance. Moreover, narrative text is a difficult material for students of SMP Negeri 2 Kepanjen to master. The researcher found that the learning by doing method initiated by Dewey would help students to better understand narrative texts. The researcher tried to apply this method to students in grade 9 ASMP N 2 Kepanjen for the 2020-2021 school year. After applying the method initiated by Dewey, there was a 
significant improvement in the ability to understand narrative texts. This can be seen from the value they get. The increase in value reached $31.4 \%$.

Keywords: Narrative Text, Learning by doing Method, pandemic period, online

\section{PENDAHULUAN}

Masa pandemi Covid 19 adalah saat saat yang sulit bagi semua warga Indonesia. Ini berdampak di semua aspek kehidupan. Termasuk di dunia pendidikan. Apalagi kita terbiasa dengan paradigma dan kebiasaan bahwa untuk belajar harus didampingi guru. Budaya kita belum sampai pada budaya otodidak yakni budaya belajar dan mengembangkan kemampuan individu secara mandiri. Kemampuan menggunakan teknologi dan kemampuan untuk membeli alat komunikasi masyarakat Indonesia yang masih rendah menambah permasalahan semakin kompleks.

Namun situasi pandemi yang tidak memungkinkan kita untuk melakukan pembelajaran secara tatap muka. Pendidikan dan pembelajaran tidak boleh berhenti apapun situasinya. Ini membuat semua elemen masyarakat berpikir. Termasuk para stakeholder pendidikan negeri ini sehingga mengambil keputusan untuk tetap melaksanakan pendidikan dengan melakukan pembelajaran jarak jauh ( PJJ) secara daring/online. PJJ menjadi satu- satunya solusi yang harus ditempuh di masa pandemi.

Masalah baru mulai bermunculan dengan keputusan pemerintah untuk melaksanakan pembelajaran jarak jauh secara daring. Mulai dari daya beli masyarakat yang rendah untuk beli alat komunikasi modern, sampai terbatasnya kemampuan kognitif orang tua untuk ikut mendampingi putra putrinya mengerjakan tugas sekolah. Bahasa Inggris adalah mata pelajaran yang paling tidak di kuasai oleh siswa dan juga orang tua siswa, ini bisa dipahami karena bahasa Inggris adalah bahasa asing. Sementara teks naratif termasuk salah satu teks yang paling tidak di kuasai oleh siswa kelas IXA SMP Negeri 2 Kepanjen.

Permasalahan utama yang dihadapi siswa kelas IXA SMP Negeri 2 Kepanjen dalam pembelajaran tentang teks naratif yaitu : kurangnya pemahaman tentang the social function of the text, the generic structure and the language feature of narrative text (Kurikulum,2013) Serta rendahnya kemampuan penguasaan vocabulary siswa sehingga nilai yang dicapai siswa jauh di bawah KKM. Dalam masa pandemi tentu sangat sulit untuk menjelaskan lebih dalam tentang kepada siswa. Apalagi membuat siswa mau belajar lebih, tentu lebih sulit karena pembelajaran jarak jauh ( PJJ) secara online/daring.Sementara itu metode yang digunakan oleh guru selama ini belum mampu mengatasi permasalahan di atas karena tidak sesuai karakteristik siswa dan cenderung membosankan sehingga siswa tidak termotivasi.Jelas, pembelajaran ini sangat tidak efektif atau dengan kata lain pembelajaran tersebut tidak berhasil (gagal). Uraian tersebut diatas merupakan kegagalan terhadap hasil dan dalam proses belajar.

Strategi pembelajaran yang tepat dan menarik bisa membantu memecahkan masalah yang dihadapi siswa di masa pandemi Selama pembelajaran daring, beberapa kendala dialami siswa, kendala utama adalah kebosanan yang dirasakan siswa, pembelajaran daring yang menarik harus di ciptakan oleh guru bagi siswa (Anugrahana (2020). Setelah mempelajari situasi saat pandemi, penulis menemukan metode bahwa learning by doing (belajar sambil mengerjakan) adalah cara terbaik untuk membuat siswa belajar. Banyak pendidik berpendapat bahwa model belajar learning by doing ialah sebuah metode yang mampu merangsang siswa guna bersungguh-sungguh dalam proses belajar mengajar sehingga keaktifan murid dapat meningkat dengan signifikan.

Penggagas metode learning by doing adalah John Dewey adalah seorang filsuf dari Amerika Serikat, Dewey juga dianggap oleh aliran fungsionalisme sebagai seorang pemikir bergaya praktis dan pragmatis, di dalam ilmu pendidikan ia menganjurkan teori dan metode learning by doing. Menutut Dewey (2012) model pembelajaran learning by doing adalah gagasan tentang sebuah konsep belajar yang menerapkan pemikiran bahwa melakukan (doing) adalah proses belajar (learning), yaitu sebuah pandangan tentang pendidikan pragmatisme yang didasarkan dua alasan penting: yang pertama adalah suatu takdir Tuhan 
bahwa anak merupakan makhluk ciptaan Tuhan yang tidak pasif, yang kedua adalah melalui bekerja/ melakukan aktifitas (by doing) yaitu bahwa siswa perlu terlibat dalam proses belajar secara langsung dan spontan juga pengalaman adalah cara terbaik dari proses pembelajaran. Metode ini diyakini akan membantu siswa untuk menumbuhkan kemampuan belajar aktif pada proses pembelajaran.

Pembelajaran dengan metode learning by doing, umumnya lebih dapat menghemat waktu dibandingkan dengan metode pembelajaran lainnya. Hal ini disebabkan karena dengan praktek langsung, otomatis siswa akan mempelajari lebih dalam tentang the social function of the text, the generic structure and the language feature of narrative text (Kurikulum,2013), serta vocabulary. Reese (2011) mengungkapkan bahwa learning by doing artinya belajar dari pengalaman sebagai akibat langsung dari tindakan orang, seperti belajar dari melihat perform orang lain, membaca instruksi atau deskripsi orang lain atau mendengar instruksi atau pembelajaran. Tentu saja sambil melihat, membaca dan mendengar, mereka melakukan, lebih lanjut di katakan bahwa learning by doing memiliki keutamaan karena ini adalah learning by self-shaping atau belajar dengan membentuk diri menjadi optimis dalam bertindak lebih efektif dan tertib dalam proses belajar.

Memperkuat pendapat dewey, Siregar (2017) menyatakan bahwa konsep learning by doing terbukti efektif dalam memperdalam dan mempercepat pemahaman peserta pelatihan terkait durasi pelatihan yang terbatas karena metode ini mampu menumbuhkan motivasi belajar, membelajarkan dengan memperhatikan perbedaan individual. Hal ini gagasan utama pendidikan , membelajarkan dengan umpan balik, membelajarkan dengan pengalihan/ transfer hasil belajar ke dalam situasi nyata.

Berdasarkan beberapa referensi diatas penulis yakin bahwa penggunaan metode "Learning By Doing" akan mampu mengatasi masalah yang di hadapi yaitu memahami teks naratif. Hal ini diperkuat oleh Heering (2012) bahwa metode "Learning By Doing" diyakini bisa meningkatkan kompetensi bagi siswa, keahlian, pengalaman, mulai dari siswa di tingkat sekolah sampai universitas. Lebih lanjut Smart(2017) menyebutkan bahwa learning by doing adalah strategi untuk melibatkan siswa secara aktif dalam pembelajaran.

Dan pemilihan whatsapp sebagai media sosial online untuk share tugas pada pembelajaran daring adalah pilihan yang paling tepat karena whatsapp adalah aplikasi sejuta umat yang dimiliki oleh semua kalangan mulai dari kalangan bawah sampai kalangan atas. Juga whatsapp adalah aplikasi paling murah dan terjangkau. Dan di SMP Negeri 2 Kepanjen di bentuk grup whatsapp kelas dan grup orang tua sebagai media komunikasi guru- siswa, dan guru-orang tua.

\section{METODE PENELITIHAN}

Penelitihan Tindakan kelas ini dilakukan di SMP Negeri 2 Kepanjen Kabupaten Malang saat pandemi covid 19. Responden adalah siswa Kelas IXA tahun pelajaran 2020-2021 dengan tujuan mengatasi masalah di kelas ini yaitu belum tercapainya target pembelajaran. naratif pada pembelajaran semester I secara daring ( online). Adapun rekapitulasi jumlah siswa 9A dapat dilihat dari table berikut ini:

\begin{tabular}{|c|c|c|c|}
\hline \multicolumn{4}{|c}{ Tabel 1 : Rekapitulasi jumlah siswa kelas 9A } \\
\hline Kelas & Jumlah Putra & Jumlah Putri & Jumlah siswa \\
\hline 9A & 16 & 14 & 30 \\
\hline & Sumber: Data Skunder Terolah (2021) \\
\hline
\end{tabular}

Alur yang digunakan dalam penelitihan ini adalah Tahap Perencanaan (Planning) menerangkan tentang persiapan pelaksanaan penelitian seperti rencana pelaksanaan pembelajaran dan instrumen pengamatan (observasi)., Tahap Pelaksanaan (Acting) dilakukan kegiatan implementasi atau penerapan perencanaan tindakan. Di dalam kegiatan implementasi ini, maka guru (peneliti) harus mentaati perencanaan yang telah disusun.,Tahap Pengamatan 
(Observing), pada tahap ini ada dua kegiatan yang akan diamati, yaitu kegiatan belajar peserta didk dan kegiatan pembelajaran, yang terakhir adalah Tahap Refleksi (Reflecting) Kegiatan ini berupa diskusi hasil pengamatan yang dilakukan oleh kolaborator dengan guru pelaksana (peneliti). Hasil refleksi dapat digunakan sebagai bahan pertimbangan dalam merancang siklus berikutnya (Sumarso, 2018)

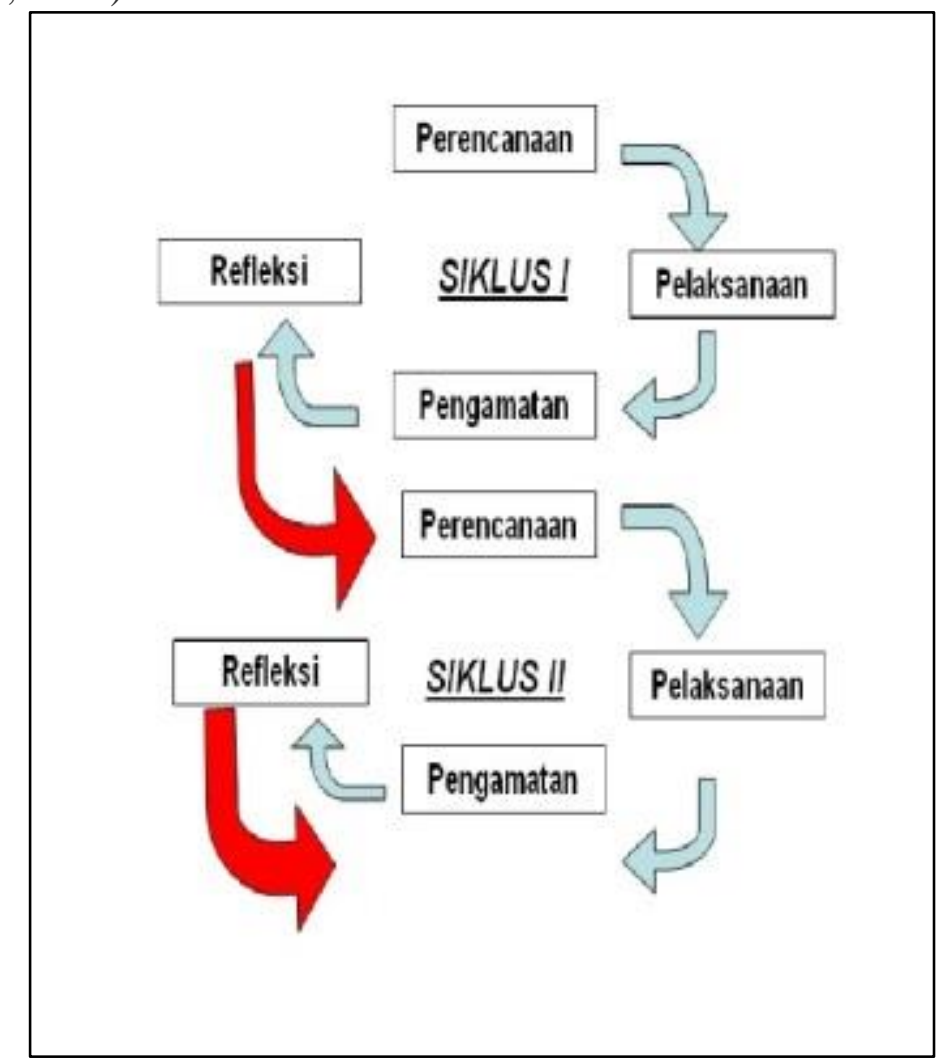

Gambar 1. Alur pelaksanaan PTK (Sumarso, 2018)

Pada penelitihan ini, metode yang digunakan adalah "Learning By Doing" adalah kegiatan belajar sambil langsung parktik melakukan apa yang dipelajari. Pada siklus 1: Siswa bercerita dengan menggunakan teks naratif dan menumpulkan dalam bentuk voicenote. Dan pada Siklus2: Siswa bercerita kemudian merekamnya dan mengumpulkan video story telling dengan mengaplikasikan teks naratif. Kemudian siswa mengunggah video yang dibuat dalam YouTube. Salah satu kriteria penilaian adalah jumlah "like" yang di dapat dari viewer.

\section{HASIL DAN PEMBAHASAN}

Sebelum pelaksanaan penggunaan metode learning by doing, Peneliti mengamati bahwa kemampuan siswa kelas IX A dalam memahami teks naratif masih rendah. Sehingga hasil test siswa kelas IX ternyata masih jauh dari harapan. Ini dapat di baca dari tabel berikut ini. Hasil ini sangat jauh dari KKM. KKM yang di tetapkan di SMP Negeri 2 Kepanjen adalah 75. Ini bisa dilihat dari perolehan siswa yang terlampir dalam table berikut ini

Tabel 2. Hasil nilai pratindakan

\begin{tabular}{|l|l|}
\hline Nilai Tetinggi & $\mathbf{8 0}$ \\
\hline Nilai Terendah & $\mathbf{2 5}$ \\
\hline Nilai rata rata & $\mathbf{5 2 . 4}$ \\
\hline \multicolumn{2}{|l|}{ Sumber: Data Primer Terolah (2021) } \\
\hline
\end{tabular}

SIKLUS 1 :

Pada siklus 1 Peneliti mencoba membuat PPT dan menampilkan video untuk menjelaskan materi tentang teks naratif. Metode learning by doing diterapkan dengan 
menyuruh siswa bercerita dengan menggunakan teks naratif dan mengirimkan hasilnya dalam bentuk voicenote story-telling. Tapi hasilnya belum maksimal. Hasil Pengamatan tentang pemanfaatan media dan istrument kurang maksimal. Sehingga hasil test siswa kelas IXA ternyata masih jauh dari harapan. Ini dapat dibaca dari tabel berikut ini. Hasil ini sangat jauh dari KKM. KKM yang di tetapkan di SMP Negeri 2 Kepanjen adalah 75. Hal in I bisa dilihat dari tabel berikut ini

Tabel 3. Hasil Nilai siklus 1

\begin{tabular}{|l|l|}
\hline Nilai Tertinggi & $\mathbf{8 3}$ \\
\hline Nilai Terendah & $\mathbf{3 3}$ \\
\hline Nilai rata rata & $\mathbf{6 1}$ \\
\hline \multicolumn{2}{|c|}{ Sumber: Data Primer Terolah (2021) } \\
\hline
\end{tabular}

Peneliti mencoba mengkaji penyebab dari kegagalan siklus ini. Dan ditemukan beberapa fakta bahwa siswa kurang bersemangat dalam bercerita dan terkesan kurang menyiapkan diri. Sebagian besar siswa hanya membaca teks naratif hasil browsing di internet. Tentu saja hasilnya kurang maksimal karena siswa tidak mencoba memahami lebih dalam tentang teks naratif.

\section{SIKLUS 2}

Pada siklus ke2, peneliti mencoba memodernisasi metode learning by doing dengan menyuruh siswa bercerita dengan menggunakan teks naratif dan mengirimkan tugas dalam bentuk video story telling yang telah di unggah dalam YouTube. Hasil yang tidak terduga terjadi. antusiasme dan semangat siswa dalam mempelajari dan mengerjakan tugas naratif teks meningkat. Hampir semua siswa berlomba untuk menyajikan video terbaik. Apalagi salah satu kriteria penilaian adalah mendapatkan like yang banyak dari viewer. Hasil dari siklus2 bisa di lihat dari tabel berikut.

Tabel 4. Hasil Siklus2

\begin{tabular}{|l|l|}
\hline Nilai Tertinggi & 90 \\
\hline Nilai Terendah & 75 \\
\hline Nilai rata rata & 84 \\
\hline
\end{tabular}

Sumber: Data Primer Terolah (2021)

Perbandingan hasil pra-tindakan, siklus 1 dan Siklus 2 terlihat terjadi kenaikan yang cukup signifikan. Hal ini bisa disimpulkan dan dilihat dari tabel berikut ini

Tabel 5 : Perbandingan hasil dari masing masing tindakan yang dilakukan peneliti

\begin{tabular}{|l|c|c|c|} 
& \multirow{2}{*}{ PRA-TINDAKAN } & \multicolumn{2}{|c|}{ PASCA TINDAKAN } \\
\hline Nilai Tetinggi & $\mathbf{8 0}$ & $\mathbf{8 3}$ & SIKLUS 2 \\
\hline Nilai Terendah & 25 & 33 & 90 \\
\hline Nilai rata rata & 52.4 & 61 & $\mathbf{7 5}$ \\
\hline Sumber: Data Primer Terolah (2021) & & 84 \\
\hline
\end{tabular}

Sementara persentase peningkatan hasil belajar siswa sebelum dan setelah tindakan terjadi peningkatan bisa dilihat dari grafik berikut ini: 


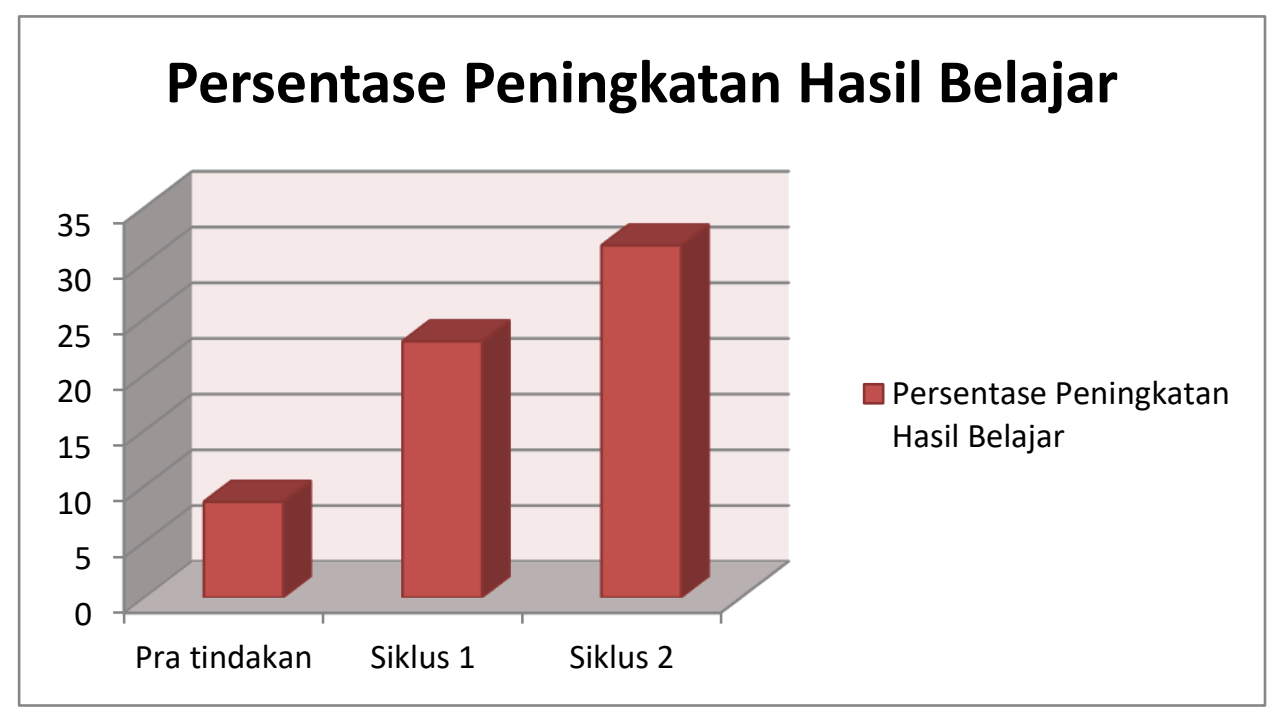

Gambar 2. Grafik Persentase peningkatan hasil belajar

Keberhasilan pemilihan metode dan penerapannya dalam mengatasi permasalahan yang muncul, tentunya tidak lepas dari adanya faktor-faktor pendukung. Faktor-faktor tersebut adalah Antusiasme siswa yang besar terhadap tugas yang diberikan, pemberian reward terhadap keberhasilan siswa, baik secara verbal maupun non-verbal.melaui jumlah like yang diperoleh, pengemasan pembelajaran yang dilakukan sedemikian rupa sehingga siswa merasa enjoy dan tidak terbebani seperti ketika pembelajaran dilakukan secara konvensional, kerjasama dan respon yang baik dari kepala sekolah dan dari guru-guru lain dan MGMP bidang studi bahasa Inggris, memadukan pelajaran dengan menggunakan social media yang memang sedang trendy dan sangat dekat dengan dunia siswa sekarang ternyata cukup efektif dalam mendongkrak semangat siswa untuk melakukan hal terbaik yang bisa mereka lakukan.

\section{KESIMPULAN}

Berdasarkan hasil analisis dan pembahasan tentang peningkatan kemampuan memahami teks narative siswa dengan membuat video story telling di masa pandemi di kelas IX A-C SMP Negeri 2 Kepanjen dapat ditarik kesimpulan melalui metode learning by doing dapat meningkatkan kemampuan siswa untuk memahami teks naratif di kelas IX SMP Negeri 2 Kepanjen, terjadi peningkatan sebesar 31,4 \%, ini lebih besar 11,4\% dari target semula yaitu terjadi kenaikan $20 \%$,melalui metode learning by doing memotivasi siswa untuk mengikuti proses pembelajaran menjadi lebih meningkat, sehingga siswa menjadi lebih aktif dan memperoleh hasil yang jauh lebih memuaskan.

Berdasarkan hasil yang diperoleh dari digunakannya metode learning by doing dalam pembelajaran di kelas inklusif, ternyata media tersebut telah memberikan kontribusi yang cukup berarti terhadap peningkatan motivasi belajar siswa, sehingga dapat meningkatkan hasil belajar siswa. Dengan demikian, metode ini terbukti mampu meningkatkan pemahaman siswa tentang teks naratif seyogyanya dapat digunakan oleh guru-guru yang lain, terutama di sekolahsekolah yang menyelenggarakan pendidikan inklusif sebagai salah satu alternatif dalam meningkatkan kualitas pembelajaran.

Adapun beberapa hal yang perlu diperhatikan berdasarkan temuan-temuan yang diperoleh dari pembelajaran dengan menggunakan metode ini untuk perbaikan pembelajaran pada waktu yang akan datang adalah sebagai berikut: Bagi guru bidang studi bahasa agar mengembangkan, bagi guru bidang studi lain agar menyesuaikan isi metode ini dengan materi pada pelajaran yang bersangkutan. Karena pada dasarnya metode ini fleksible, bisa digunakan untuk semua jenjang satuan pendidikan juga semua materi pelajaran, pendekatan dan bimbingan terhadap siswa hendaknya dilakukan secara lebih intensif agar kebutuhan siswa dapat terpenuhi dengan baik, sehingga hasil belajar yang dicapai dapat lebih optimal. 


\section{DAFTAR PUSTAKA}

Anugrahana, A (2020)."Hambatan, Solusi dan Harapan: Pembelajaran Daring selama Masa Pandemi Covid-19 Oleh Guru Sekolah Dasar" dalam Jurnal Pendidikan dan Kebudayaan - from ejournal.uksw.edu

Dewey, J (2012)." John Dewey and Experiential Learning: Developing the theory of youth work " dalam Journal “ Youth \& Policy No. 108/March 2012

Heering, P, Roland Wittje (2013). "Learning by Doing: Experiments and Instruments in the History of Science Teaching" dalam. Johns Hopkins University Press, Volume 54, Number 1, January 2013

Kemdikbud. (2013). "Kurikulum SMP 2013 Edisi Revisi 2018” Kurikulum Bahasa Inggris Kelas 9

Reese, HW (2011).“The Learning-by-Doing Principle" dalam Jurnal Behavioral Development Bulletin Volume 11 2011.West Virginia University

Siregar, F F(2017)."Thesis: Penerapan Pembelajaran "Learning By doing” pada pelatihan public speaking di lembaga Training Indonesia" from https://core.ac.uk/download/pdf/223125848.pdf

Smart, KL, Nancy Csapo (2007). "Learning by Doing: Engaging Students Through LearnerCentered Activities" dalam SAGE JOURNALS Published December 1, 2007

Sumarso (2018). "Panduan Tahapan Perumusan Judul Penelitian Tindakan Kelas PTK," from https://goeroendeso.wordpress.com/2018/03/19/panduan-tahapan-perumusan-judulpenelitian-tindakan-kelas-ptk/

Sumarso. (2018). “Membuat Laporan Penelitian Tindakan Kelas” from https://www.academia.edu/12708615/Laporan_Penelitian_Tindakan_Sekolah 